\title{
Application of the R2Smesh approach for the accurate estimation of photon radiation dose fields around activated ITER in-vessel components
}

\author{
Haibo LIU, Ulrich Fischer, Arkady Serikov, Pavel Pereslavtsev, Keitaro Kondo*
}

Karlsruhe Institute of Technology, Hermann-von-Helmholtz-Platz 1, 76344 Karlsruhe, Germany

\section{Introduction}

The R2Smesh ("Rigorous 2-step") approach [1] can be utilized to calculate photon radiation dose fields around activated components which are moved from the irradiation site in ITER to some external location. In this work, we applied the R2Smesh approach to dose rate analyses of ITER in-vessel components in a transfer cask.

\section{Neutron flux and activation calculations for the ITER in-} vessel components

$>$ The blanket first wall module and the divertor cassette were analyzed.

> The first wall geometric model [2] and the calculated decay gamma source 2D distribution are shown below.
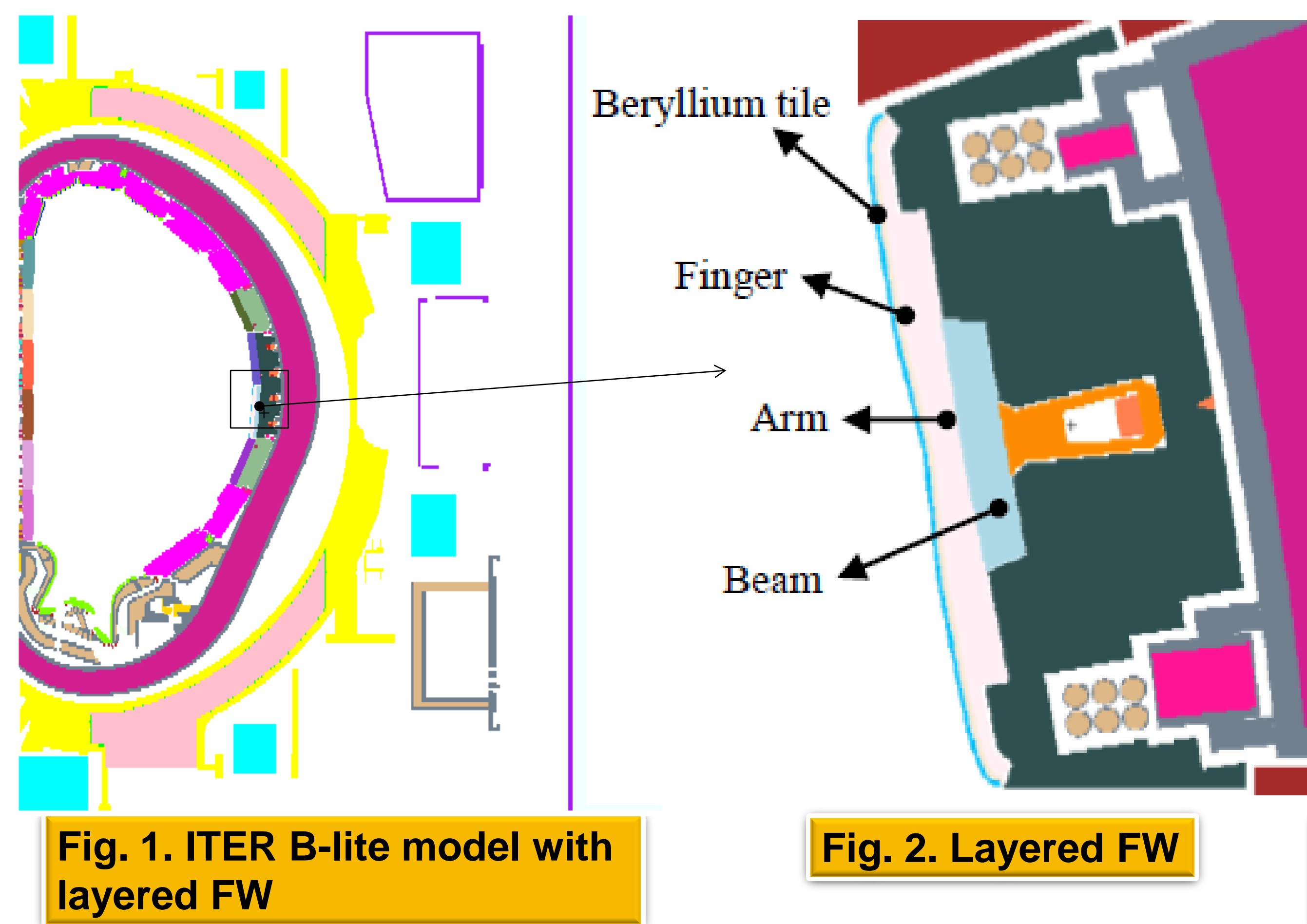

Fig. 2. Layered FW

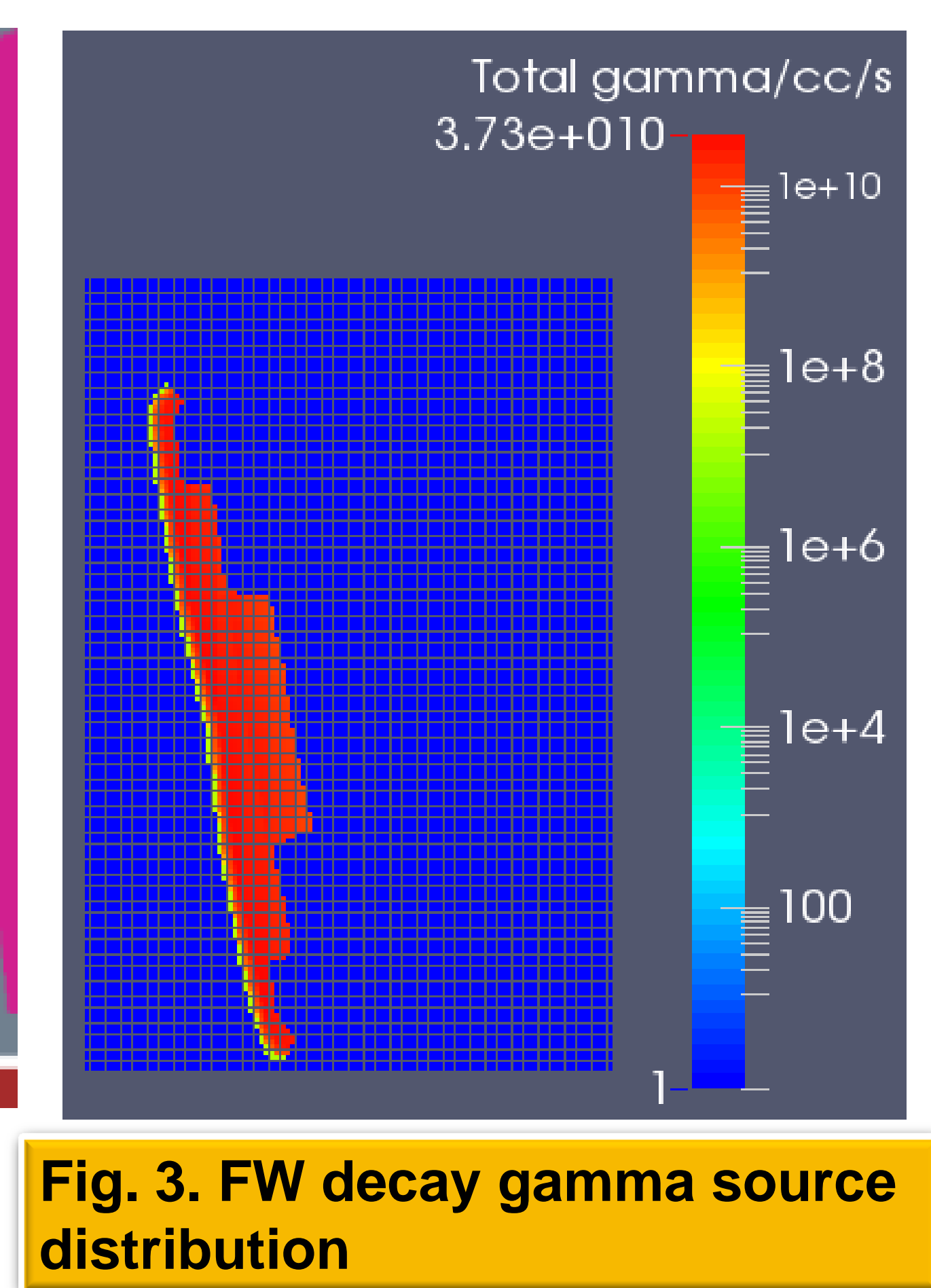

\section{Dose rate calculation}

> The ITER transfer cask is modeled as a $7 \mathrm{~cm}$ thick steel plate. The activated components were removed from the ITER model and integrated into this transfer cask model.

> The associated decay gamma source distributions were transferred to the cask and overlaid to the geometric models of the activated components using the R2Smesh approach.

- The photon transport geometric model and its dose rate map for the FW case and the divertor case are shown in the following figures.

cask top surface

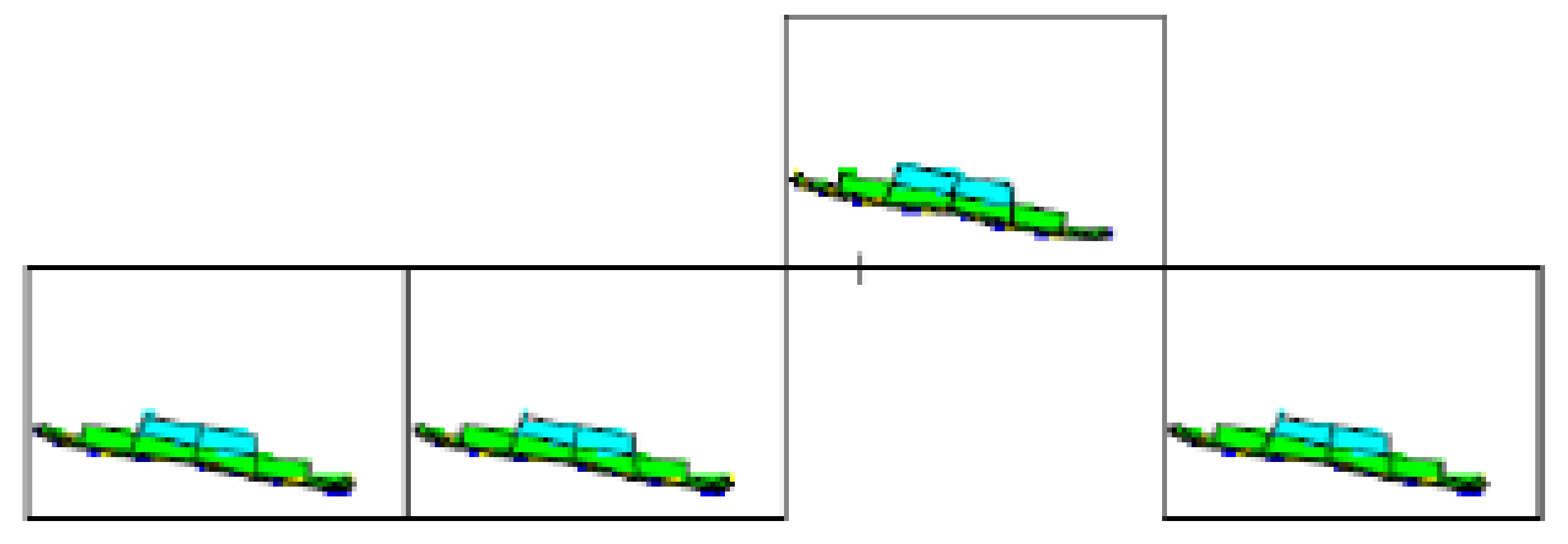

cask bottom steel plate

Fig. 4. MCNP model of the transfer cask loaded with four FW modules

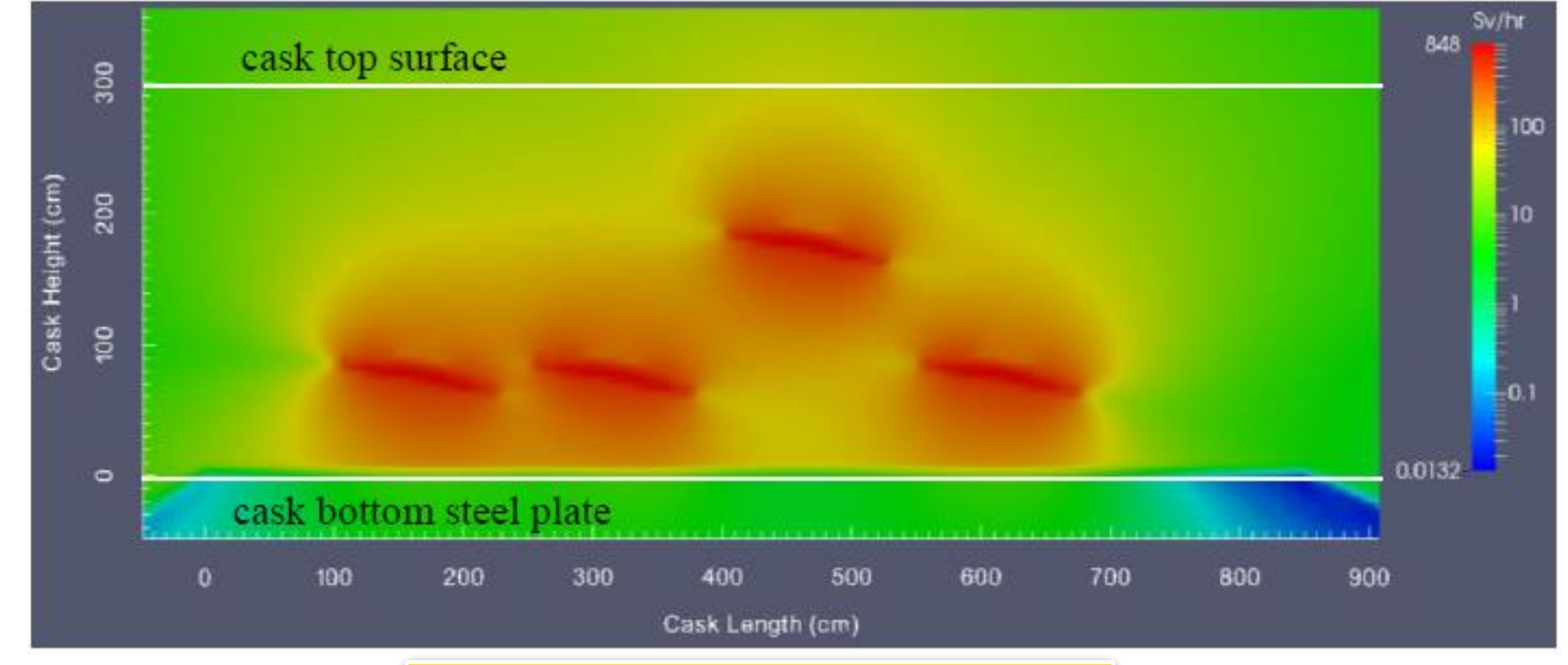

Fig. 5. Dose rate map around the cask

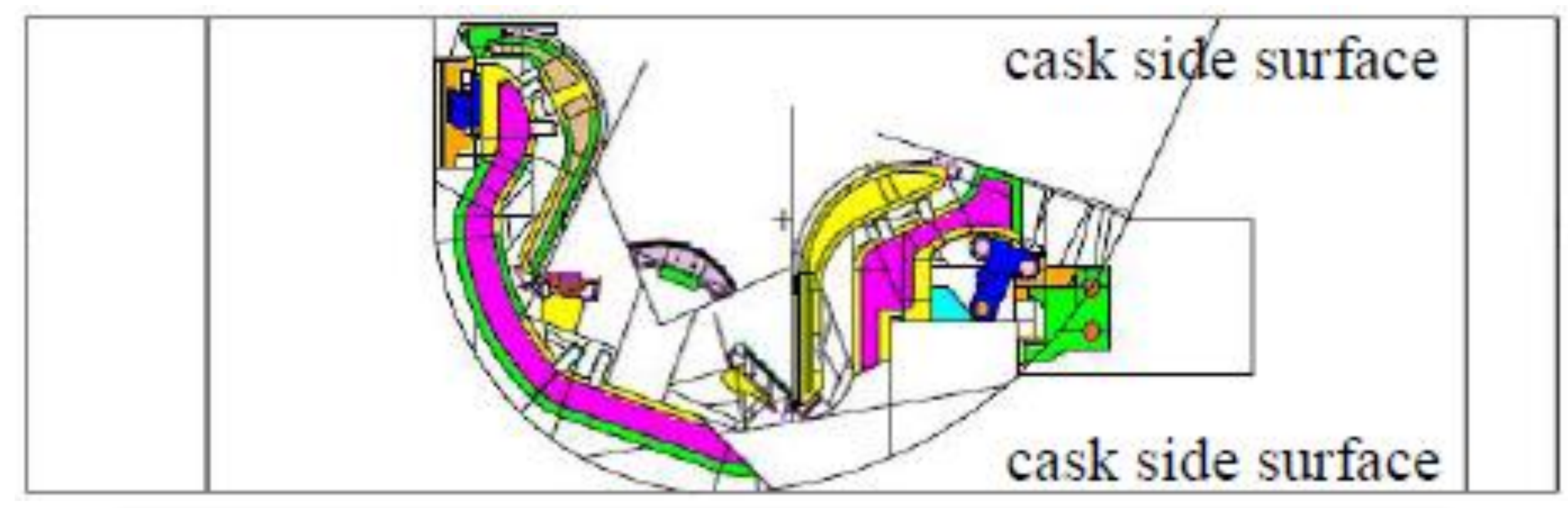

Fig. 6. MCNP model of the transfer cask loaded with divertor cassette

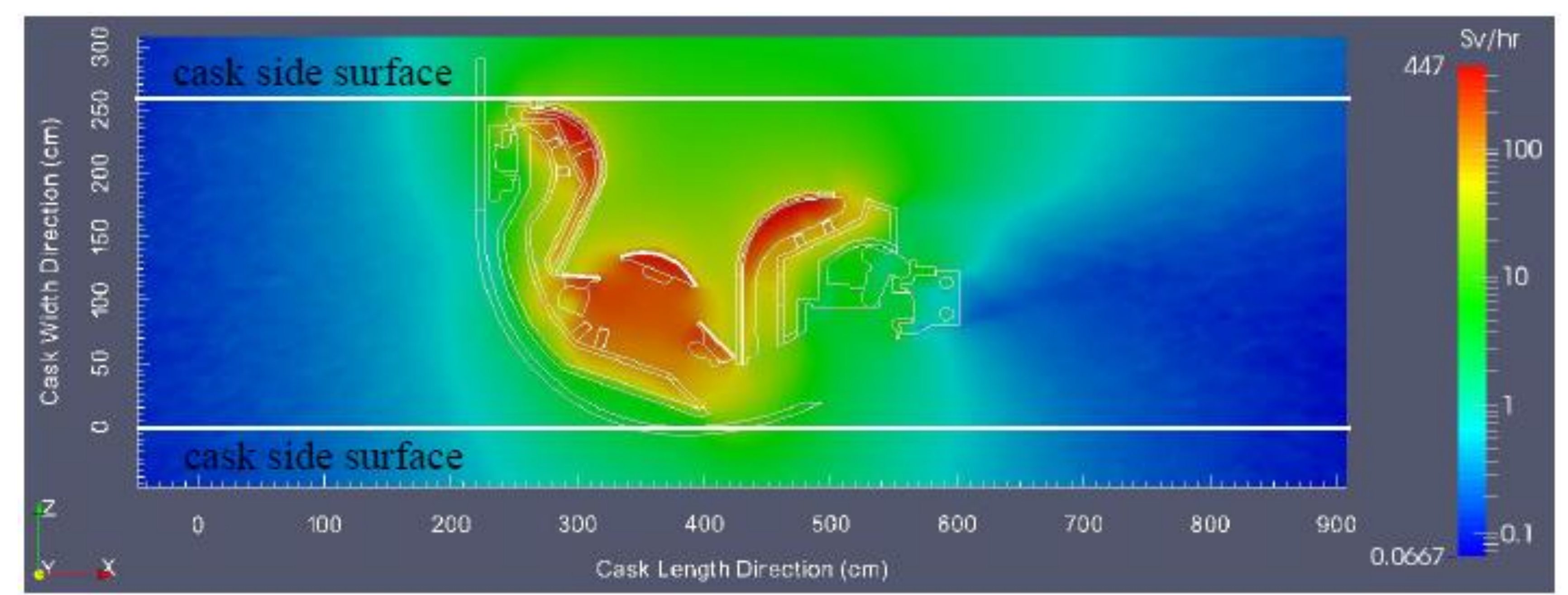

Fig. 7. Dose rate map around the cask

The dose rate level below the cask is much lower than above because of the $7 \mathrm{~cm}$ thick cask bottom steel plate shielding.

> The relative errors for the dose rates are less than about $10 \%$ for most of the cask volume.

\section{Summary}

The R2Smesh approach was utilized to assess the dose rate distribution around the ITER transfer cask loaded with activated in-vessel components. The results show that this approach is a versatile tool for performing such analyses.

\section{Acknowledgments}

This work was funded by the ITER service contracts Nr. ITER/CT/13/4300000763. The support from Dr. Michael Loughlin and Dr. Miguel Dapena at ITER IO is appreciated.

The views and opinions expressed herein do not necessarily reflect those of the ITER Organization.

[1] M. Majerle, et al., Fusi. Engi. \& Des. 87, 443-447, 2012

[2] M. Sawan, Private Communications, ITER IDM, 9AWXY6, 2012.

${ }^{*}$ Now working at JAEA. 